International Journal of Instruction e-ISSN: 1308-1470 • www.e-iji.net

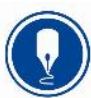

January $2020 \bullet$ Vol.13, No.1

p-ISSN: 1694-609X

pp. $747-766$

Received: $15 / 05 / 2019$

Revision: 08/09/2019

Accepted: 13/09/2019

OnlineFirst:09/12/2019

\title{
A Case Study on Improving Reading Fluency at a University in the UAE
}

\author{
Jenny Eppard
}

College of Education, Zayed University, Dubai, UAE, jenny.eppard@zu.ac.ae

\section{Sandra Baroudi}

College of Education, Zayed University, Dubai, UAE, baroudi.sandra@gmail.com

\section{Aicha Rochdi}

Academic Bridge Program, Zayed University, Dubai, UAE, aicha.rochdi@zu.ac.ae

$$
\mid
$$

Students native to the Arabian Gulf region often struggle with reading skills. The purpose of this study was to explore the reading habits and reading culture of Emirati undergraduate students and to investigate the use of a particular reading strategy (Listening While Reading) on undergraduate Emirati students reading rate and comprehension. This case study was conducted through a mixed method research design. It was carried out with sixty-one SLL (second language learners) undergraduate students. By assigning them into two groups, the experimental group (28 students) was given books with an auditory component, while the control group (33 students) was given the same books but without the auditory component. both positive and negative reflections from teachers and students on different aspects of the LWR experiences are discussed. Qualitative findings revealed more contextualized results related to the lack of comprehension improvement such as, lack of reading habits. Additionally, quantitative results indicated that the performance of students in reading rate and accuracy improved over time. However, reading comprehension did not improve. Additionally, implications in terms of the use of the LWR in English language classes for practitioners are discussed as well as recommendations for future studies.

Keywords: reading fluency, accuracy, automaticity, reading rate, second language learning, United Arab Emirates context, reading comprehension, listening while reading

\section{INTRODUCTION}

All students who enter national public universities in the United Arab Emirates (UAE) must take an English language exam. Students who obtain below a certain score are required to take pre-sessional foundation English classes. Test results indicate that students struggle the most with reading. Yet, at the time of this study, little was known about the students' individual reading levels or how to implement a reading program

Citation: Eppard, J., Baroudi, S., \& Rochdi, A. (2020). A Case Study on Improving Reading Fluency at a University in the UAE. International Journal of Instruction, 13(1), 747-766. https://doi.org/10.29333/iji.2020.13148a 
whereby the students are placed at a reading level based on these individual needs. Instead, courses were developed using an integrated skills model. They could pass the class, even though they had weak reading skills, and moved on to the next course. Reading difficulties with this population have been well documented in Al Murshidi (2014) and O'Sullivan (2004). For teachers to best determine how to support students in reading, data needs to be collected on why students struggle with this skill and on which strategies best substantiate student learning.

The fundamental purpose of reading can be defined as assigning and/or deriving meaning from text. Reading then can be defined as the process of deconstructing a written text while, simultaneously, assigning meaning to it (Grabe \& Stoller, 2013; Hudson, 2007). At the tertiary level, skilled reading comprehension is a complex cognitive process that involves many higher-level cognitive skills such as making predictions and inferences, extracting and synthesizing information, recognizing author's stance, and distinguishing between opinion and fact. In addition to these skills, readers at the college level also need to be able to utilize contextual and structural clues to form a logical understanding of the communicative purpose of a text. Although the central issue in this paper is reading comprehension, the focus is also on a specific reading component that is central to reading comprehension namely reading fluency.

The rationale of this focus is that a large body of research has shown that the higherlevel processes that influence and determine effective comprehension do not become fully operational until the reader has acquired a reasonable level of fluency (Adams, 1990; Gough \& Tunmer, 1986; Hoover \& Gough, 1990; Kuhn \& Stahl, 2003; Perfetti, 1985; Sticht \& James, 1996; Vellutino, Scanlon, \& Tanzman, 1994). In other words, for college students to read a text and achieve adequate comprehension, they should be able to read the text in question effortlessly. One of the goals of this study is to examine whether reading fluency can be improved by using a Listening While Reading (LWR) intervention to support reading improvement at Zayed University's, a United Arab Emirates (UAE) national university, EAP classrooms.

\section{Significance of the Study}

Little is known about the capability of university students in the UAE when it comes to reading fluency and the strategies employed when reading a text. Hence, it is important first to look at the quality of reading in the UAE where increasing English language proficiency and reading quality is a top priority of educational reform (O'Sullivan, 2016). A primary issue with understanding the educational needs of this specific population is a lack of quality research available; therefore, educational specialists often rely on studies conducted in Western countries. This is turn makes it difficult for teachers to determine the reading needs for their individual students. This study hopes to shed some light on the subject.

Studies of assisted reading have demonstrated the effectiveness of Listening while Reading (LWR) in promoting reading processes. This study aims to explore the use of LWR in this context. More specifically, this case study aims to investigate the effectiveness of LWR in promoting improvements in Emirati SLL students' reading 
fluency, with a focus on reading rate and accuracy. This is beneficial for this context specifically as this population was detected with significant deficit in their English language reading skills and lack of motivation towards reading in general (Al-Nafisah, 2011; Gobert, 2009; Mourtaga, 2006; O’Sullivan, 2009).

The goal of this paper was also to investigate reading fluency, reading culture and reading habits among university students in the United Arab Emirates enrolled in foundational English courses by addressing these questions:

1. What are students' perceptions of LWR intervention towards reading comprehension?

2. To which extent could students' reading habits be explained by their reading culture and exposure in the UAE context?

3. Does LWR effect reading rate, accuracy, and/or comprehension with population?

\section{LITERATURE REVIEW}

\section{Reading Fluency and Reading Comprehension}

Fluent reading has been recognized as a central component of skilled reading. It refers to the ability to read easily and accurately (Burt, Peyton, \& Van Duzer, 2005). It is also considered by organizations such as the National Reading Panel, the National Institute for Literacy, and the National Center for the Study of Adult Learning and Literacy (NCSALL) as a major component for optimum reading development (Kuhn, Schwanenflugel, \& Meisinger, 2010). While reading fluency has been well investigated in the K-12 environment, little research has been conducted at the university level. Taguchi (1997) found that reading rates increased for Japanese university students but fluency was not transferred when asked to read silently on a new test.

Reading fluency involves several components. One characteristic of a fluent reader includes the reading of text at a conversational level which can be replicated at different times and with various texts Another characteristic is the reading of text in a flowing manner without interruption (Hudson, Lane \& Pullen, 2005). Therefore, reading fluency is determined through the measurement of rate and accuracy through oral reading. Research suggests that oral reading fluency has a strong concurrent relationship to reading comprehension (Fuchs et al., 2001; Hudson et al., 2008; Kuhn et al., 2010; Kuhn \& Stahl, 2003). In recent years, instructional methodologies have been developed that are aimed at improving reading fluency. Of interest to this paper is the investigation of the effect of assisted reading, specifically listening while reading (LWR).

\section{Listening While Reading (LWR)}

Reading fluency can be fostered through a process called assisted reading or listening while reading (LWR) (Rasinski \& Hoffman, 2003). LWR involves having the student read silently while simultaneously listening to a fluent rendition of the reading passage. LWR helps develop reading fluency through a neurological impress model. While reading along, a more fluent reader creates alternative neural pathways through a strong multisensory reinforcement technique (Kuhn \& Stahl, 2003). The auditory version of the 
reading can be performed by a fluent adult reader or by the use of various technological devices.

LWR proved to enhance young and adult students reading fluency. LWR reported positive results on reading fluency for elementary readers even when variations of LWR as an instructional method were used (Carbo, 1978; Chomsky, 1976; Heckelman, 1969). It enhanced comprehension rates for second grade students when implemented on both easy and more difficult passages (Blonder et al., 2018). Additionally, when compared with repeated reading for third graders, listening to the text being read by the instructor while they read along (LWR) proved to develop reading fluency and general proficiency in reading (Rasinski, 2006). Furthermore, Reissner (1997) described LWR as a 'time efficient method to bring those at-risk to a comparable level to those who have been exposed to a print rich environment' (p. 298). Along with oral reading improvement, Reissner (1997) also found that this method improved attitudes, motivation, and selfconfidence. Moreover, when LWR was employed for Spanish-speaking students who were learning English as a second language (ESL), it improved reading rates, decreased error rates, and resulted in improved comprehension skills (VanWagenen, Williams, \& McLaughlin, 1994). Additionally, when implementing this technique for one year with 230 Japanese undergraduate students, it was shown that their reading rate and vocabulary recognition as measured by the Test of English as a Foreign Language (TOEFL) significantly improved. However, no effect was seen on their general English proficiency (Gobel \& Kano, 2014). Hence, it is argued whether the gain in reading comprehension is the result of the amount of reading practice or the result of learning a new skill, connecting and linking text to oral language (Kuhn \& Stahl, 2003). In other words, it is not certain if LWR is a successful method alone or if it is affected by external factors.

\section{Running Records}

Keeping running records has been well documented as a tool to inform teaching practice. Lipp and Helfrich (2016) argue that running records have the ability to inform teachers about individual students' strengths and weaknesses in fluency. The authors claim that they only need about one hundred words to understand their students' struggles. Fountas, Pinnell, and Le Verrrier (2001) claimed that running records should assess oral rate, oral accuracy and comprehension (orally or through written questions). Using this method, teachers note issues that students may have with reading and use this information to inform best classroom practices. Many of these assessments are used as informal assessments. Frequent monitoring help teachers determine the correct reading level for their students; therefore, ensuring that the available reading for that student is not too difficult or too easy.

\section{Reading in the Arab World}

While literacy levels in the Arab World have increased in the last twenty years, Mourtaga (2006) argued that some of the Arab populations have limited literacy skills at least in part due to a lack of reading habits even at home (Gobert, 2009; Khreisat \& Kaur, 2014; O’Sullivan 2009)). A significant deficit in English language reading skills 
may lead to difficulties with reading at the university level (O'Sullivan, 2009; O'Sullivan, 2016). O'Sullivan (2009) adds that the 'negative prior learning experiences at school' is an additional problem with reading. This is rooted to the outdated schoolbased language teaching methodologies used by teachers who teach to the exams, rather than, focusing on strategies that would ultimately develop students' reading skills. Limited use of libraries by both teachers and students and lack of resources necessary are further inhibitors (O’Sullivan, 2009).

An absence of motivation and interest are attributed to weak reading habits in the Arab world (Al-Nafisah, 2011). Having poor reading habits and limited exposure to print are identified as indicators of poor reading comprehension (Stanovich, 2009). Indeed, exposure to print augments the lexical semantic knowledge and a large vocabulary correlates positively with reading acquisition. Thus, being frequently exposed to print, is especially advantageous in widening the semantic lexicon, which in turn facilitates and enhances reading acquisition (Stanovich, 2009). As such, students need to know 98\%$99 \%$ of the words before adequate comprehension is possible (Hirsh \& Nation, 1992).

In the UAE, reading habits are associated with certain factors. For instance, Emirati female students conveyed their strong interest and self-motivation when reading the Quran (Kamhieh, 2012). Others expressed their willingness to read based on the teacher's request or the main character of the story, the length of the textbook, or on the literary quality and cost (Khreisat \& Kaur, 2014). Despite this fact, these students recognized the importance of reading for improving their language and academic achievement, as they are aware of the necessity for assisted reading techniques for the development of their reading fluency and comprehension (Khreisat \& Kaur, 2014). For instance, college students in the UAE expressed their preferences for LWR (Gobert, 2009). While their preferences were investigated, there was no empirical research to date that supported the effect of assisted reading techniques such as LWR on college students' reading fluency and comprehension in the UAE.

\section{METHOD}

\section{Context}

The United Arab Emirates (UAE) strives to provide students with a first-rate educational system and a progressive national curriculum by ensuring high literacy rates, integrating modern education programs, and providing equal opportunities for all students (Ministry of Education, 2017). Therefore, educational reform was influenced mainly by technological innovations, enhancement of the curriculum, and best teaching strategies to provide learners with a postive learning environment (Abu-Samaha \& Shishakly, 2008). The country has a wide range of universities in both the public and private sectors where publicly funded higher education is offered mainly to nationals.

This study was conducted in one of these publicly funded universities in the UAE, Zayed University. It has two modern campuses in Abu Dhabi and Dubai that welcomes both national and international students. However, most of the undergraduate students are Emirati whose first language is Arabic. Most of these students come from government schools that follow the standard national curriculum. In these schools, 
Arabic is the main language of instruction for all subjects while English is taught and is used as a second language for teaching technical or scientific subjects only. Despite this fact, higher education institutions in the UAE provide all their courses in English except for Islamic and Arabic courses. Therefore, to support students' deficit in English and strengthen their reading skills, the university provides a language support program called the Academic Bridge Program (ABP) for up to one year before entering contentrich classes. Students are enrolled in the ABP to study and practice writing, reading, listening and speaking in English. The program consists of three levels. Students in ENG 020 scored the lowest on the entrance exam. Students in ENG 030 passed ENG 020 or scored well enough on the entrance exam to be placed in this level. Students in ENG 040 passed ENG 030 or scored well enough on the entrance exam to be placed in this level and is therefore the highest level. The entrance exam is the Common Educational Proficiency Assessment (CEPA) which is administered nationwide by the Ministry of Education of the UAE and is regarded as both reliable and valid (Coombe \& Davidson, 2014). The scores determines whether the student is eligible to enter an academic program directly without the need of a foundation program in English (www.adm.moe.gov.ae).

\section{Design}

This population, as previously mentioned, struggles with reading as indicated in multiple tests and through research. Therefore, several teachers decided to conduct research to determine if a common strategy used in the K-12 and L1 environment would work in this setting. This case study used a mixed method design. The purpose of the study was to explore the possibility of implementing LWR in this context and to both better understand and document student reading habits and experiences. In alignment with previous studies that researched the impact of reading on second language learning through pre-and post-test comparison designs (Elley \& Mangubhai, 1983; Nakanishi, 2015 ) and due to the uniqueness of the context of this study regarding the deficiency of reading habits in general and specifically in English as a second language, this exploratory study will follow a mixed method design to investigate and increase awareness about the topic through both qualitative and quantitative research (Creswell, 2009). Both groups tested at the same reading levels and were asked to read books at this level. The LWR option was provided only to the experimental group. A pre-test and post-test were completed by the two groups at the beginning and at the end of the study. After conducting the experiment, qualitative data was collected. Interviews with teachers and focus groups with the experimental group only were conducted in order to collect in-depth views and perceptions of students' experiences when listening while reading (Seidman, 2013).

\section{Participants}

Sixty-one undergraduate Emirati students and two teachers from Zayed University in the UAE participated in the study. Teachers are both qualified and have more than 7 years of experience in teaching SLLs in the UAE. All the students were enrolled in the Academic Bridge Program (ABP). The ABP is an English Language foundation program that supports undergraduates who have not met the requirements of EMSAT 
English Score of 1250 or an academic IELTS score of 5.5 or a TOEFL iBT $71+$ score. These students are enrolled in the ABP for a period of up to 4 semesters before being eligible to join the majors. Upon completion of the ABP, students must have an IELTS exit score of 5.5 or above (www.zu.ac.ae).

$17 \%$ of the students' participants were male while $83 \%$ were female. The students who participated in this study were all enrolled in four different introductory level (ENG 020) classes. The inclusionary criteria to participate in the study were that the student is between 18 and 22, is enrolled full time in one of the different classes and has never had a history of language disorders or delays, social, emotional, or psychiatric problems (via teacher and personal report). The classes were assigned to one of two groups: experimental group $1(n=28)$, and control group $2(n=33)$. The participants in the two groups had a CEPA score between 150 and 171. The mean scores were respectively: 156.25 (range 150 to 171$)(\mathrm{SD}=6.08), 155$ (range= 152 to 169$)(\mathrm{SD}=3.76)$. Based on these results, the students in this study were shown to be at risk and therefore, may struggle with an English-medium university curriculum. They were placed in the lowest English level as a result. The attrition rate was high for this level. Before the EMSAT, the university used the Common Educational Proficiency Assessment (CEPA) to determine placement in the Academic Bridge Program. The CEPA exam is an assessment developed in the UAE and was given to all students exiting high school. After entering the university, all students in the ABP are once again tested with a writing exam to make sure that they have been placed in the correct level.

\section{Materials}

Participants were given access to an online professional reading program called Reading A-Z using an iPad App. Reading A-Z is designed to be used with native English speakers as well as second language learners (https://www.readinga-Z.com). There were several reasons for choosing this particular program: a) it was available on campus b) it is based on best practices and is developed with SLLs in mind c) it has a rich collection of levelled books; d) it includes tests that allow to establish a baseline and monitor students' progress; e) students are able to listen and read simultaneously. Even though the books in this program were geared towards young learners, the fact that they provided clear and interesting illustrations along with the reading text, and that their length allowed them to be read in one class period made them an adequate choice for the intervention. Using children's literature to further adult literacy is a method that has been used in the SLL classroom and that has yielded positive results (Chen, 2012; Garcia, 2007; Smallwood, 1998).

Assessing reading fluency was conducted through the administration of the two types of assessments that are included in the A-Z Reading App. The first type of fluency assessment is a one-minute timed reading of a passage to measure the number (reading rate) and accuracy of words read. In this study, reading rated was used as a measure of automaticity. According to Paris \& Carpenter (2003) commercial reading inventories are generally reliable and valid. DeGennaro (2018) found that Reading A-Z analyzes text using both qualitative and quantitative measures to include the following: 
Table 1

Text Analysis

\begin{tabular}{lll}
\hline Qualitative & - predictability of text \\
& - text structure and organization \\
& - illustration support \\
\hline Quantitative & - total word count \\
& - number of different words \\
& - ratio of different words to total words \\
& - number of high frequency words, ratio of high frequency words to total words \\
& - ratio of low frequency words to total words \\
& - sentence length \\
& - sentence complexity (p. 28)
\end{tabular}

The testing was administered by the researcher who visited each class and tested the students individually. A running record was administered as recommended at each of the testing periods, the students were given a one-minute reading. The researcher started the stopwatch when the student began the first word of the passage (student did not read titles). The researcher told the student that if she or he has trouble (struggling for more than 3 to 5 seconds), that they will say the word so she or he can keep reading. After one minute, the researchers said 'Stop,' stopped the stopwatch, and circled the last word read. Students then answered comprehension questions to measure comprehension through a professionally developed question set.

\section{Procedures}

At the onset of the study, a pre-test was administered to obtain a baseline reading rate, accuracy score and comprehension score. Students were then given books at the same reading level and were allotted a minimum twenty minutes a day for reading in class for the period of 8 weeks as this was the maximum amount of time allowed in this setting. Participants in the experimental group (group 1) were given books and were asked to listen while reading while participants in the control group were given the same books but were asked to read without listening (group 2).

A running record was kept for each participant as recommended by Hudson, Lane and Pullen (2005) who argue that contextualized reading, oral reading and timed reading can accurately access students reading rate and accuracy. The researchers collected scores from each subject in tasks of rate, accuracy and comprehension. Each subject was tested two times. Thus, each subject had two scores: a score collected before the treatment (pre-test), and a score collected after the end of intervention (post-test).

Due to the originality of this study within the UAE context, qualitative data was highly needed to elaborate on the quantitative findings to further understand them the reading culture in the UAE. Therefore, at the end of the study, 4 focus groups with 7 students each (28 students in total) and two interviews with two faculty members were conducted to explore their perceptions of LWR. Questions were divided into three main themes 
namely, reading habits, use of technology while reading, (see Appendix 1). A total of 10 semi-structured questions were asked.

Interviews with teachers were conducted to collect their perceptions of the impact that the LWR had on students' accuracy and comprehension. Teachers were asked a total of five semi-structured questions (see Appendix 1). As this was an exploratory study questions were developed to determine general perceptions as experienced by the teachers. However, follow-up questions could include more specific questions based on the teachers' individual experiences and as topics emerged.

Interviews were analyzed using Rubin and Rubin's (2011) interviewing procedure that employs in-depth interviewing techniques. As such, the interpretive analysis was done with the extensive focus on the three main themes. After obtaining participants' consent and assuring anonymity, the interviewer took hand notes of the responses. The interviewer also kept a reflective journal to support the data analysis process by including the researchers' feelings, ideas, and impressions (Creswell, 2009).

\section{Data Analysis}

Focus group and interviews were manually transcribed. NVivo was used to analyze the transcribed data and extract categories and themes based on Spradley's (1979) taxonomic analysis, starting with broad question and then narrowing them to gather more specific information when needed. This analysis technique helped the data to be coded into themes and then categories. Two researchers independently analyzed the data to ensure reliability. Data was coded based on themes. Quotes as evidences were assigned for each theme. The Statistical Package for the Social Sciences (SPSS) version 23 was used to analyze the quantitative portion of the data and compare mean differences on the pre and post-test using a t-test.

\section{FINDINGS}

This section is divided into two parts: the qualitative outcomes and the quantitative results. The qualitative portion underscored several important views that the students had toward reading. Two main themes emerged based on the analysis of the responses given during focus groups with students and during interviews with faculty members including perceptions of listening while reading and reading culture.

\section{Perceptions toward LWR on Reading Fluency and Comprehension}

Analysis of the data highlighted the views that the students and the teachers had toward LWR. Students claimed that reading and listening to the same story simultaneously was beneficial for several reasons such as an improved acquisition of new vocabulary. Fiftythree percent of students commented on improvements made in vocabulary acquisition. Examples of these comments include:

Researcher: "Can you explain any positives that you have noticed?"

Student A: "increased my vocabulary"

Student J: "some words we can't read but when we listen, we understand better" 
Twenty-five percent of students indicated that they understood the content better because of LWR, for example:

Student B: "I understand more"

Student C: "some of the questions are difficult but with the listening they were ok"

Seventeen percent of students indicated that LWR assisted with pronunciation, while eight percent indicate that it helped with spelling:

Student I: "we learn how to spell the word"

Student K: "with the listening you know how to pronounce the words which help"

When asked "Can you explain any negatives that you have noticed?", twenty-one percent of students argued that the texts were difficult. Some examples of these responses are as follows:

Student A: ".... they were sometimes difficult"

Another student stated that while the reading was easy, the vocabulary was sometimes difficult

Student B: "it (the reading) is easy, but there are some words that we cannot say, and we cannot understand it"

Still other students found the questions difficult:

Student C: "and I don't understand the new words and it is difficult"

The teachers argued that the experience was beneficial for students. While they were not able to determine with certainty if students' reading improved, they felt that students enjoyed the experience and were usually ready to read, without hesitation, during the portion of the class allocated to LWR on the iPad. One teacher highlighted this by saying:

Teacher A: "I know they enjoyed reading. I could see that. I can't really say that they are reading better. Once I said let's do it, they didn't complain until maybe the last week and that could be for many reasons because they had many exams that week"

Another teacher concurred by claiming:

Teacher B: "Some of them wanted to read in their free time at home. They liked the variety of topics of the books. Another teacher highlighted that they thought the ubiquitous aspect of reading on the iPad was beneficial: 'I can read anywhere"

Reading culture

In order to form an accurate understanding of the topic within the context of the learner, students were asked during the focus groups to describe their experiences with reading 
as children as well as their habits since then. Twenty-five percent of the students indicated that a family member read to them during childhood. However, the majority indicated that they were not read to as a child. Still, some stated that while they were not read to as children, they were told oral stories, without text, about their country's past and local folklore. One student inferred to a possible generational gap between younger parents and older grandparents when she stated that:

Student O: "my grandmother told me the story, but my mom and dad read me the story"

In general, these reading habits, or lack thereof, remained consistent until the students attended university. While seventy-one percent of the students had read some for school, in either Arabic or English, they did not read a lot of books before coming to the university. One student elaborated on this point:

Student N: “yes, not much because I don't like to read, I never read”

In general, this was the consensus. Although, all students preferred to read in Arabic instead of English only a few read in Arabic frequently. Thirty-nine percent indicated that when they read it was in Arabic. They found the following types of text the most interesting: poems (11\%), Islamic stories (3\%), stories (79\%) and the news (46\%). Even though the students were interested in these text types, they still were not interested in forming reading habits with longer texts that were time-consuming.

While most students were not readers in the traditional sense, sixty-eight percent often read through social media and/or through social networking Apps. Two of their favourite Apps/sites were Twitter and Blackberry Messenger. When they were asked why they preferred to read using these tools, they stated that the text 'was short' and that 'the vocabulary was not difficult'. They read in both English and Arabic when reading on social media sites.

\section{LWR Intervention}

To investigate the effect of listening while reading on the development of fluency skills specifically reading rate, accuracy, and reading comprehension, an independent samples t-test was conducted to compare the reading rate for both groups for both the baseline and the post-test. Despite that comparisons of means on pre-and post-test showed that the experimental group (chart 1) and control group (chart 2) performed better over time, there was no significant difference between both groups (table 2). Pre-test scores on the reading fluency rate showed no significant difference for both the control group and the experimental $[\mathrm{t}(59)=-1.211, \mathrm{p}>.05$, two-tailed]. The same is true for the post-test $[\mathrm{t}$ $(59)=-1.164, p>.05$, two-tailed]. Additionally, there was no significant difference in means for both groups in pre-test $[\mathrm{t}(59)=-1.470, \mathrm{p}>.05$, two-tailed] and post-test [t $(59)=-1.146, p>.05$, two-tailed] for the reading accuracy. This suggests that students reading rate improved over time but maybe not due to the implementation of the LWR intervention.

As for the results of reading comprehension, subjects in the control group scored significantly better in reading comprehension on the pre-test than the students in the 
experimental group ( $\mathrm{p}=.024$, two tailed). However, at the end of the study, both groups did not show a significant difference in reading comprehension on the post-test $(p=$ .616 , two tailed). This indicates that the intervention may not have had the desired results. However, it must be emphasized that this is an exploratory study and definitive conclusion cannot be made. All of the quantitative results are indicated in Table 2 below.

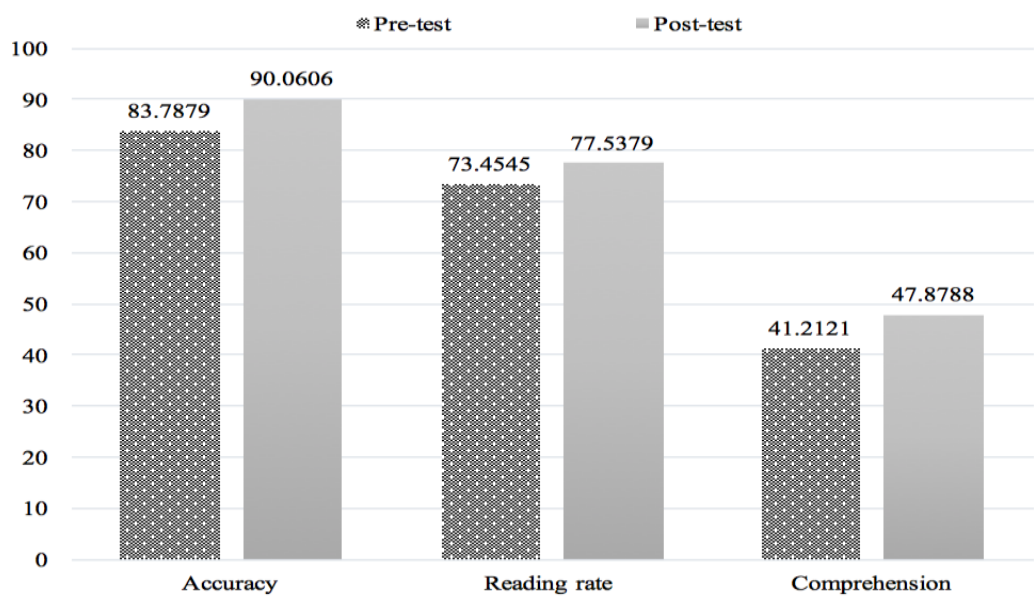

Figure 1

Experimental Group

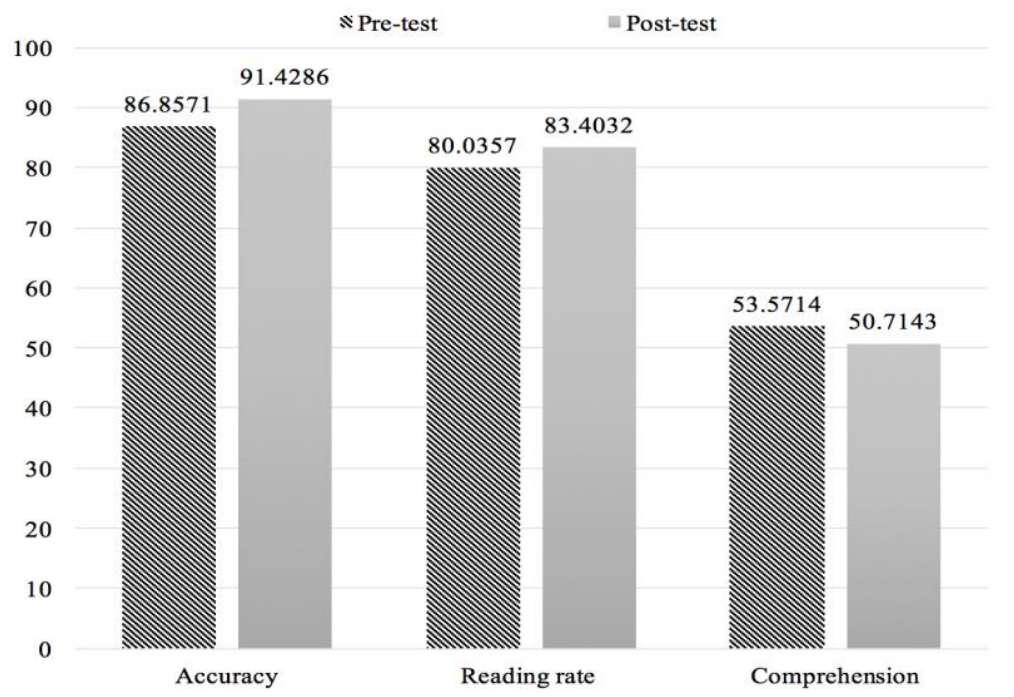

Figure 2

Control Group 
Table 2

Pre-and Post-test Results on Accuracy, Reading Rate, and Comprehension

\begin{tabular}{|c|c|c|c|c|c|c|c|}
\hline \multicolumn{8}{|l|}{ Pre-test } \\
\hline Variable & Group & $\mathrm{N}$ & M & SD & df & $\mathrm{T}$ & $\mathrm{p}$ \\
\hline \multirow{2}{*}{ Accuracy } & Experimental & 28 & 86.8571 & 6.53035 & 59 & -1.470 & 0.147 \\
\hline & Control & 33 & 83.7879 & 9.25931 & & & \\
\hline \multirow{2}{*}{ Reading rate } & Experimental & 28 & 80.0357 & 20.94169 & 59 & -1.211 & 0.322 \\
\hline & Control & 33 & 73.4545 & 21.32793 & & & \\
\hline \multirow{2}{*}{ Comprehension } & Experimental & 28 & 53.5714 & 22.47868 & 59 & -0.504 & 0.024 \\
\hline & Control & 33 & 41.2121 & 19.32576 & & & \\
\hline \multicolumn{8}{|l|}{ Post-test } \\
\hline Variable & Group & $\mathrm{N}$ & M & $\mathrm{SD}$ & $\mathrm{df}$ & $\mathrm{T}$ & $\mathrm{p}$ \\
\hline \multirow{2}{*}{ Accuracy } & Experimental & 28 & 91.4286 & 4.63024 & 59 & -1.146 & 0.256 \\
\hline & Control & 33 & 90.0606 & 4.65658 & & & \\
\hline \multirow{2}{*}{ Reading rate } & Experimental & 28 & 83.4032 & 18.88128 & 59 & -1.164 & 0.782 \\
\hline & Control & 33 & 77.5379 & 20.22053 & & & \\
\hline \multirow{2}{*}{ Comprehension } & Experimental & 28 & 50.7143 & 18.44483 & 59 & -2.310 & 0.616 \\
\hline & Control & 33 & 47.8788 & 24.46395 & & & \\
\hline
\end{tabular}

\section{DISCUSSION}

Teachers and students' perceptions of LWR were explored through focus groups and interviews. In alignment with Reissner (1997) teachers felt that the LWR experience improved students' motivation to read. Data gathered during the focus group discussions emphasized how students perceived an improved level of vocabulary, spelling and pronunciation improved. Similar to Al- Nafisah (2011), students in this study expressed that they have weak reading habits in the sense that they do not read for pleasure because:

- The unavailability of reading materials

- Beliefs of having better things to do than reading

- Difficulty of reading materials provided by the English department

- Beliefs that improving reading is not as important as improving other language skills

- Lack of family reading habits 
It was also evident from the analysis of the focus group interviews that the participants had limited exposure to print. As children, the participants interviewed reported not being read to. Having weak reading habits and limited exposure to print were identified as indicators of poor reading comprehension (Stanovich, 2009). Indeed, it is reported in literature that exposure to print helps augment the lexical semantic knowledge and gaining a large vocabulary correlates positively with reading acquisition. Thus, being frequently exposed to print, is especially advantageous in widening the semantic lexicon, which in turn facilitates and enhances reading acquisition. Stanovich (2009) describes this relationship as one where 'the rich get richer' or as the 'Mathew effect' to which it is highly needed for students to know $98-99 \%$ of the words before adequate comprehension was possible (Hirsh \& Nation, 1992).

To determine student's reading levels, students' reading rate, accuracy and comprehension levels were studied using a readily available reading program. The results of the post-test showed that both groups improved over time for the reading rate and accuracy tasks. However, there was no significant difference between scores of experimental and control group students. This may mean that the improvement among readers is due mainly to the extensive reading of books that have reduced vocabulary range and simplified grammatical structures (Blevins, 2005; Elley \& Mangubhai, 1983, Nakanishi, 2015; Nation \& Cruz, 2009; Samuels, 2012; Robb \& Susser, 1989). Reading comprehension improved in group 2 only.

These results were in line with the idea that comprehension is a complex construct that requires the synergy of multiple factors. Comprehension can fail when students have problems with one or more of the following: (a) decoding words, (b) reading text with appropriate speed and accuracy (fluency); (c) understanding the meanings of words; (d) relating content to prior knowledge; (e) applying comprehension strategies; and (f) monitoring understanding (Blonder et al., 2018; Carlisle \& Rice, 2002; National Institute for Literacy, 2001; RAND Reading Study Group, 2002). Therefore, studies that investigate the synthesis of reading with any of these skills may be useful. This is especially true to develop an accurate picture of reading with this population.

\section{LIMITATIONS}

This study used a reading program developed for the K12 environment. It would be perhaps more beneficial to use a similar program for adults that is valid and reliable for this population specifically. From this study, students appeared to appreciate the ubiquitous nature of the reading program. While it was obvious that much of the material available was universal in content and may appeal to adult learners, a program for the specific population may be more motivational. Additionally, students could have experienced fatigue by the time of the post-test which could have impacted their scores. Another limitation is related to the type of instrument chosen for this study. While the informal reading assessment was validated before with adults (Worthy \& Viise, 1996) and with students whose English is a foreign language (Avalos et al., 2007), was not used previously within this context, it. Another limitation with this study is the teacher factor. Students in one group may have performed differently from another group due to the influence of the teacher. Another limitation is the frequency of the running record 
assessments. Fountas, Pinnell, and Le Verrrier (2001) argue that running records should be used frequently to best inform practice. The nature of the environment limited the frequency of the running records administered during the research.

\section{CONCLUSION AND RECOMMENDATIONS}

Despite that this study has several limitations, it represents the first exploratory study involving LWR as an assisted reading technique on reading rate, accuracy and comprehension among undergraduate SLL students in the United Arab Emirates (UAE). Using a case study design, results indicated that students reading rate and accuracy improved over time for all classes and marginally more so for the experimental group. Additionally, there was no significant change in the comprehension scores at the end of the study. In contradiction to Rasinski and Hoffman (2003) and VanWagenen et al. (1994) findings, LWR intervention in this context had little effect on reading fluency and comprehension. This could be explained due to the weak reading habits and lack of motivation and interest that were reported by the participants in the interviews. While these results may not be generalizable on a large scale and perhaps given more time, the results would be different for this population. However, in the end, the study showed a process of a way to perhaps think about increasing reading skills in an adult population that struggles with reading in a second language.

This study recommends future research using a larger sample size and for a longer period. In addition, similar studies could be carried out to draw reliable conclusions. Other studies, outside of fluency per se, could focus on question type and compare the performance in reading comprehension as a function of the language used to ask the comprehension questions. Still other studies could test vocabulary acquisition as well as spelling improvement due to listening while reading. Future research could also investigate the effectiveness of LWR by comparing two groups with the same text but one in English and the other in Arabic or by comparing it with another type of evidencebased reading intervention. Such experimental comparison could support teachers with evidence-based data related to the effectiveness of interventions that are designed to improve fluency and comprehension specifically within an SLL sample.

\section{REFERENCES}

Abu-Samaha, A. M., \& Shishakly, R. (2008). Assessment of school information system utilization in the UAE primary schools. Issues in Informing Science and Information Technology, 5, 525-542. doi:10.28945/1026.

Adams, M. J. (1990). Beginning to read: Thinking and learning about print. Cambridge, MA: MIT Press.

Al Murshidi, G. (2014). UAE university male students' interests impact on reading and writing performance and improvement. English Language Teaching, 7(9), 57-63.

Al-Nafisah, K. (2011). Saudi EFL students' reading interests. Journal of King Saud University-Languages and Translation, 23(1), 1-9. doi:10.1016/j.jksult.2009.07.001. 
Avalos, M. A., Plasencia, A., Chavez, C., \& Rascón, J. (2007). Modified guided reading: Gateway to English as a second language and literacy learning. The Reading Teacher, 61(4), 318-329.

Blevins, W. (2005). The importance of reading fluency and the English language learner. The Language Teacher, 29(6), 13-16.

Blonder, M., Skinner, C. H., Ciancio, D., Cazzell, S., Scott, K., Jaquett, C., Ruddy, J. \& Thompson, K. (2018). A comparison of comprehension accuracy and rate: Repeated readings and listening while reading in second-grade students. Contemporary School Psychology, 23(3), 231-244.

Burt, M., Peyton, J. K., \& Van Duzer, C. (2005). How should adult ESL reading instruction differ from $\mathrm{ABE}$ reading instruction. Center for Adult English Language Acquisition. Retrieved from http://www. cal. org/caela/esl_resources/briefs/readingdif. html.

Carbo, M. (1978). Teaching reading with talking books. The Reading Teacher, 32(3), 267-273.

Carlisle, J., \& Rice, M. S. (2002). Improving reading comprehension: Research-based principles and practices. York Press.

Carlton, P. M., \& Walkenshaw, D. (1991). Diagnosis of learning disabilities in postsecondary institutions. Journal of Postsecondary Education and Disability, 9, 197206.

(n.d.) The Common educational proficiency assessment [Measurement instrument]. Retrieved from www.adm.moe.gov.ae.

Chen, M. L. (2012). Effects of integrating children's literature and DVD films into a college EFL class. English Teaching, 11(4), 88-98.

Chomsky, C. (1976). After decoding: What? Language Arts, 53(3), 288-314.

Coombe, C., \& Davidson, P. (2014). Common educational proficiency assessment (CEPA) in English. Language Testing, 31(2), 269-276.

Creswell, J.W. (2009). Research design: Qualitative, quantitative, and mixed methods approaches. London: SAGE.

DeGennaro, D. N. (2018). The relationship between metacognitive strategies and reading comprehension in fifth grade students (Unpublished doctoral dissertation). University of West Georgia.

Elley, W. B., \& Mangubhai, F. (1983). The impact of reading on second language learning. Reading research quarterly, 19(1), 53-67. doi: 10.2307/747337

Fountas, I. C., Pinnell, G. S., \& Le Verrier, R. (2001). Guided reading. Portsmouth, NH: Heinemann. 
Fuchs, L. S., Fuchs, D., Hosp, M. K., \& Jenkins, J. R. (2001). Oral reading fluency as an indicator of reading competence: A theoretical, empirical, and historical analysis. Scientific studies of reading, 5(3), 239-256. doi:10.1207/S1532799XSSR0503_3.

Garcia, M. D. L. P. (2007). Integrating children's literature into a college foreign language class: A teacher-researcher's perspective (Unpublished doctoral dissertation). The University of Texas at Austin.

Gobel, P., \& Kano, M. (2014). Implementing a year-long reading while listening program for Japanese university EFL students. Computer Assisted Language Learning, 27(4), 279-293.

Gobert, M. (2009). Key findings from research and implications for the classroom. In D. Anderson, M. McGuire (Eds.), Cultivating real readers (pp.53-63). Abu Dhabi: HCT.

Gough, P. B., \& Tunmer, W. E. (1986). Decoding, reading, and reading disability. Remedial and Special Education, 7(1), 6-10. doi:10.1177\%2F074193258600700104.

Grabe, W. P., \& Stoller, F. L. (2013). Teaching and researching: Reading. Routledge.

Heckelman, R. G. (1969). A neurological-impress method of remedial-reading instruction. Academic Therapy, 4(4), 277-282.

Hirsh, D., \& Nation, P. (1992). What vocabulary size is needed to read unsimplified texts for pleasure? Reading in a foreign language, 8(2), 689-689.

Hoover, W. A., \& Gough, P. B. (1990). The simple view of reading. Reading and writing, 2(2), 127-160. doi:10.1007/BF00401799.

Hudson, R. F., Lane, H. B., \& Pullen, P. C. (2005). Reading fluency assessment and instruction: What, why, and how? The Reading Teacher, 58(8), 702-714.

Hudson, R. F., Pullen, P. C., Lane, H. B., \& Torgesen, J. K. (2008). The complex nature of reading fluency: A multidimensional view. Reading \& Writing Quarterly, 25(1), 4 32. doi:10.1080/10573560802491208.

Hudson, T. (2007). Teaching second language reading. Oxford: Oxford University Press.

Kamhieh, C. (2012). The leisure reading habits of first-year, female Emirati university students: an investigation (Unpublished doctoral dissertation). Canterbury Christ Church University.

Khreisat, M., \& Kaur, S. (2014). English recreational reading habits of Arab Jordanian EFL tertiary students. Education, Business and Society: Contemporary Middle Eastern Issues, 7(1), 17-32. doi:10.1108/EBS-08-2013-0030.

Kuhn, M. R., \& Stahl, S. A. (2003). Fluency: A review of developmental and remedial practices. Journal of educational psychology, 95(1), 3-21. 
Kuhn, M. R., Schwanenflugel, P. J., \& Meisinger, E. B. (2010). Aligning theory and assessment of reading fluency: Automaticity, prosody, and definitions of fluency. Reading Research Quarterly, 45(2), 230-251. doi:10.1598/RRQ.45.2.4.

LaBerge, D., \& Samuels, S. J. (1974). Toward a theory of automatic information processing in reading. Cognitive Psychology, 6(2), 293-323. doi:10.1016/00100285(74)90015-2.

Lipp, J. R., \& Helfrich, S. R. (2016). Key reading recovery strategies to support classroom guided reading instruction. The Reading Teacher, 69(6), 639-646.

Ministry of Education (2017). The Ministry of Education Strategy 2010 - 2020. [Online]. Retrieved from https://www.moe.gov.ae/Arabic/Docs/MOE\%20_Strategy.pdf.

Mourtaga, K. R. (2006). Some reading problems of Arab EFL students. Journal of AlAqsa University, 10(2), 75-91.

Nakanishi, T. (2015). A meta-analysis of extensive reading research. Tesol Quarterly, 49(1), 6-37. doi: 10.1002/tesq.157.

Nation, P., \& Cruz, P. (2009). 4000 essential English words. Seoul: Compass Pub.

National Center for Educational Statistics. (2005). Fourth-grade students reading aloud. (Technical Report number NCES 2006-469). Washington DC: US Department of Education.

National Institute for Literacy. (2001). Put reading first: The research building blocks for teaching children to read. Jessup, Maryland: National Institute for Literacy.

National Reading Panel (2000). Teaching children to read: An evidence-based assessment of the scientific research literature on reading and its implications for reading instruction. Bethesda, MD: National Reading Panel. Retrieved from http://www.nationalreadingpanel.org/Publications/researchread.htm.

O'Sullivan, A. (2004). Reading and Arab college students: Issues in the United Arab Emirates higher colleges of technology. In Proceedings of the First International Online Conference on Second and Foreign Language Teaching and Research: Beyond Borders.

O'Sullivan, A. (2009). Reading in the Gulf: Is it time for a re-focus? Cultivating Real Readers. Retrieved from http://marifa.hct.ac.ae/2009/32.

O'Sullivan, K. (2016). Education quality in the UAE - factors in creating a knowledgebased economy. Retrieved from https://ssrn.com/abstract=3194377.

Paris, S. G., \& Carpenter, R. D. (2003). Center for the improvement of early reading achievement: FAQs about IRIs. The Reading Teacher, 56(6), 578-580.

Perfetti, C. A. (1985). Reading ability. New York: Oxford Press.

RAND Reading Study Group. (2002). Reading for understanding: Toward an $R \& D$ program in reading comprehension. Santa Monica, CA: RAND 
Rasinski, T. (2006). Reading fluency instruction: Moving beyond accuracy, automaticity, and prosody. The Reading Teacher, 59(7), 704-706. doi: 10.1598/RT.59.7.10.

Rasinski, T. V., \& Hoffman, J. V. (2003). Oral reading in the school literacy curriculum. Reading Research Quarterly, 38(4), 510-522. doi: 10.1598/RRQ.38.4.5.

Rasinski, T. V. (2004). Assessing reading fluency. Pacific resources for education and learning. Honolulu: Pacific Resources for Education and Learning.

Reissner, L. A. (1997). Using taped books with children at-risk: Four case studies. Washington DC: US Department of Education.

Robb, T. N., \& Susser, B. (1989). Extensive reading vs skills building in an EFL context. Reading in a foreign language, 5(2), 239-251.

Rubin, H.J., \& Rubin, I.S. (2011). Qualitative interviewing: The art of hearing data. New Delhi: Sage.

Samuels, S. J. (2006). Reading fluency: Its past, present, and future. Fluency instruction: Research-based best practices, 2, 3-16.

Seidman, I. (2013). Interviewing as qualitative research: A guide for researchers in education and the social sciences. New York, NY: Teachers College Press.

Smallwood, B. A. (1998). Using multicultural children's literature in adult ESL classes. ERIC, National Clearinghouse for ESL Literacy Education.

Spradley, J. P. (1979). The ethnographic interview. New York, NY: Harcourt Brace Jovanich College.

Stanovich, K. E. (2009). Matthew effects in reading: Some consequences of individual differences in the acquisition of literacy. Journal of Education, 189(1-2), 23-55 doi:10.1177/0022057409189001-204

Sticht, T. G., \& James, J. H. (1996). Listening and reading In R. Barr, P. D. Pearson, M. L. Kamil, \& P. B. Mosenthal (Eds.), Handbook of reading research (293-317). New York: Psychology.

Taguchi, E. (1997). The effects of repeated readings on the development of lower identification skills of EFL readers. Reading in a Foreign Language, 11(1), 97-119.

VanWagenen, M. A., Williams, R. L., \& Mc Laughlin, T. F. (1994). Use of assisted reading to improve reading rate, word accuracy, and comprehension with ESL Spanishspeaking students. Perceptual and Motor Skills, 79(1), 227-230.

Vellutino, F. R., Scanlon, D. M., \& Tanzman, M. S. (1994). Components of reading ability: Issues and problems in operationalizing word identification, phonological coding, and orthographic coding. In G. R. Lyon (Ed.), Frames of reference for the assessment of learning disabilities: New views on measurement issues (pp. 279-332). Baltimore, MD: Paul H Brookes. 
Worthy, J., \& Viise, N. M. (1996). Morphological, phonological, and orthographic differences between the spelling of normally achieving children and basic literacy adults. Reading and Writing, 8(2), 139-159.

\section{Appendix 1: Semi - Structured Interview Questions}

\section{Questions for Students}

1- Approximately how many books have you read before coming to class?

2- Can you share you experience and habits with reading as a child?

3- How often did you read using technology such as computers and mobile devices?

4- In what capacity did this reading take place?

5- In which ways has reading a book in class changed your perception of reading, if at all?

6- How has listening to the book while reading it on your iPad changed your habits of reading, if at all?

7- Are you more likely to read on your iPad, why or why not?

8- What benefits are there to listening to a book while reading?

9- What advantages and disadvantages are there to reading on the iPad?

10- What disadvantages are there to listening to a book while reading?

Questions for Teachers

1- In general, can you elaborate on how the reading program has been going in your class?

2- Can you explain any positives that you have noticed?

3-Can you explain any negatives that you have noticed?

4- What would you change about the reading program?

5- Have you noticed any changes in the way students read or approach reading due to this program? 